\title{
Review Article \\ The Association between rs2292239 Polymorphism in ERBB3 Gene and Type 1 Diabetes: A Meta-Analysis
}

\author{
Dingjian Wang (i) and Guixia Pan (1) \\ Department of Epidemiology and Biostatistics, School of Public Health, Anhui Medical University, 81 Meishan Road, Hefei, \\ Anhui 230032, China \\ Correspondence should be addressed to Guixia Pan; pgxkd@163.com
}

Received 3 March 2019; Revised 16 April 2019; Accepted 11 July 2019; Published 6 August 2019

Academic Editor: Konstantinos Kantartzis

Copyright (C) 2019 Dingjian Wang and Guixia Pan. This is an open access article distributed under the Creative Commons Attribution License, which permits unrestricted use, distribution, and reproduction in any medium, provided the original work is properly cited.

\begin{abstract}
Objectives. The purpose of this study was to explore the association between rs 2292239 polymorphism in ERBB3 gene and type 1 diabetes (T1D). Methods. A systematic search of studies on the association of $r s 2292239$ polymorphism in ERBB3 gene with T1D susceptibility was conducted in PubMed, Web of science, Elsevier Science Direct, and Cochrane Library. Eventually, 9 published studies were included. The strength of association between $r s 2292239$ polymorphism and T1D susceptibility was assessed by odds ratios (ORs) with its 95\% confidence intervals (CIs). Results. A total of 9 case-control studies, consisting of 5369 T1D patients and 6920 controls, were included in the meta-analysis. This meta-analysis showed significant association between ERBB3 rs2292239 polymorphism and T1D susceptibility in overall population (A vs. C, OR: $1.292,95 \% \mathrm{CI}=1.224-1.364, P_{\mathrm{H}}=0.450, P_{\mathrm{H}}$ is $\mathrm{P}$ value for the heterogeneity test). Similar results were found in subgroup analysis by ethnicity. Conclusions. ERBB3 rs 2292239 polymorphism is associated with T1D susceptibility and $r$ 2292239-A allele is a risk factor for T1D. However, more large-scale studies are warranted to replicate our findings.
\end{abstract}

\section{Introduction}

Type 1 diabetes (T1D), a kind of autoimmune disease, is characterized by the progressive loss of insulin-secreting pancreatic beta cells [1-3]. The etiology of T1D is very complex, which is affected by both genetic and environmental factors. Although it may occur at any age, compared with other age groups, the incidence of T1D in children is higher. The incidence of T1D is also significantly different due to region and ethnicity $[4,5]$. The destruction of pancreatic beta-cells and the lack of insulin lead to hyperglycemia. T1D patients require exogenous insulin to survival. Therefore, those affected patients are insulin-dependent for life $[6,7]$. The complications with T1D are serious.

$E R B B 3$ gene encodes erb-b2 receptor tyrosine kinase 3 (ErbB3), which is a member of the epidermal growth factor receptor (EGFR) family $[8,9]$. ErbB3 interacts more specifically with PIK3 regulatory subunits, which transduce signals downstream to mTOR signaling pathway and in turn regulate insulin production in beta-cells and subsequent glucose metabolism [10]. ERBB3 gene is located on chromosome 12q13; rs2292239 SNP is located in intron 7 of $E R B B 3$ gene [11, 12]. ERBB3 gene can also be expressed in pancreatic beta cells. ERBB3 gene is widely known for its role in cancer, but some studies have shown that the ERBB3 rs2292239 polymorphism might also play an important role in the pathogenesis of T1D due to immune regulation and apoptosis of beta-cells $[13,14]$.

Considering the results of ERBB3 gene polymorphism with T1D susceptibility are inconsistent [15], this discrepancy might be due to studies with small sample size, inadequate statistical power, ethnic differences, and publication bias. Therefore, it is necessary to conduct meta-analysis to explore this association.

\section{Methods}

2.1. Search Strategy. A systematic search of studies on the association of $r s 2292239$ polymorphism in ERBB3 gene with T1D susceptibility was conducted in PubMed, Web of science, 
Elsevier Science Direct, and Cochrane Library. Keywords for the search were as follows: ("ERBB3" or "rs2292239") and ("Diabetes" or "T1D") and ("polymorphism" or "variant" or "SNP" or "genotype" or "mutations"). The last search was updated on 15 January, 2019. All relevant studies were retrieved carefully.

2.2. Eligibility Criteria. The inclusion criteria were as follows: (I) studies evaluating the association between rs2292239 polymorphism in ERBB3 gene and T1D; (II) case-control studies; (III) studies based on humans; (IV) studies providing the detailed relevant genotype data of both case group and control group. Studies were excluded if (I) the study was a review, editorial, abstract, case report, or unpublished article; (II) there were nonhuman studies or animal experiments or cell experiments; (III) studies had no controls or no detailed relevant genotype data.

2.3. Data Extraction. The data of the eligible studies were extracted by one investigator (Mr.Wang). The following information was collected: name of first author, year of publication, country, ethnicity, genotyping methods, number of cases and controls in each study, genotype frequency in cases and controls, the value of $P$ in Hardy-Weinberg equilibrium (HWE), and other additional information. Different ethnicity descendants were classified as Caucasian and Asian.

2.4. Quality Assessment. The qualities of the included studies in this meta-analysis were assessed by another investigator (Dr.Pan). The quality assessment was based on the modified Newcastle-Ottawa Quality Assessment Scale (NOS). The scale consists of eight multiple-choice questions that involve subjects selection, comparability in cases and controls, and assessment of exposure. High-quality response earns a point, totaling up to nine points (the comparability question earns up to two points) [16]. The higher score indicates better quality.

2.5. Statistical Analysis. This meta-analysis was conducted following the guidelines from PRISMA and MOOSE statement $[17,18]$. Hardy-Weinberg equilibrium (HWE) was evaluated for each study by Chi-square test in control groups. And $P>0.05$ was considered as genetic balance in the study population. All statistical analysis was performed by Stata 12.0 software (Stata Corporation, College Station, TX, USA). OR and 95\% CI were used to evaluate the strength of association between ERBB3 rs2292239 polymorphism and T1D susceptibility. The $\chi^{2}$ test-based Q statistic was generally used to assess the heterogeneity. Heterogeneity was recognized as statistically significant when $P_{\mathrm{H}}<0.05$. According to the value of $P_{\mathrm{H}}$, we chose fixed-effects model or random-effects model. All subgroups were analyzed. Sensitivity analysis was used to evaluate the influence of individual study on the overall OR. Publication bias was assessed by Funnel's plot, Begg's test, and Egger's test. An asymmetric plot and the $P$ value of Egger's test or Begg's test less than 0.05 were considered as significant publication bias.

\section{Results}

3.1. Literature Search. A total of 82 studies were retrieved from PubMed, Web of science, Elsevier Science Direct, and Cochrane Library. Finally, 9 eligible studies were included in this meta-analysis. A flowchart of the included and excluded studies was shown in Figure 1.

3.2. Characteristics of the Included Studies. Table 1 showed the main features of those included studies. Those studies were published from 2009 to 2016. Nine studies involving 5369 T1D patients and 6920 controls were included in this meta-analysis. All included studies met the Hardy-Weinberg equilibrium.

3.3. Meta-Analysis of Association between rs2292239 Polymorphism and T1D Susceptibility. Meta-analysis indicated significant association between ERBB3 rs2292239 polymorphism and T1D susceptibility in the overall population (A vs. C, OR: $1.292,95 \% \mathrm{CI}=1.224-1.364, P_{\mathrm{H}}=0.450$; AA vs. $\mathrm{AC}+\mathrm{CC}$, OR: $1.426,95 \% \mathrm{CI}=1.275-1.594, P_{\mathrm{H}}=0.636 ; \mathrm{AA}+\mathrm{AC}$ vs. CC, OR: $\left.1.374,95 \% \mathrm{CI}=1.277-1.479, P_{\mathrm{H}}=0.732\right)$. Then, subgroup analysis was conducted according to ethnicity. In Caucasians, the significant association was identified in all genetic models (A vs. C, OR: $1.262,95 \% \mathrm{CI}=1.190-1.339, P_{\mathrm{H}}=0.762$; AA vs. AC+CC, OR: 1.395, 95\% CI=1.239-1.570, $P_{\mathrm{H}}=0.805 ; \mathrm{AA}+\mathrm{AC}$ vs CC, OR: $\left.1.332,95 \% \mathrm{CI}=1.228-1.446, P_{\mathrm{H}}=0.894\right)$. In Asians, the significant association was also identified in all genetic models (A vs. C, OR: 1.455, 95\% CI=1.273-1.663, $P_{\mathrm{H}}=0.388$; AA vs. $\mathrm{AC}+\mathrm{CC}, \mathrm{OR}: 1.701,95 \% \mathrm{CI}=1.214-2.384, P_{\mathrm{H}}=0.183$; $\mathrm{AA}+\mathrm{AC}$ vs. $\mathrm{CC}$, OR: $\left.1.560,95 \% \mathrm{CI}=1.322-1.841, P_{\mathrm{H}}=0.680\right)$. The forest plots for $r s 2292239$ with T1D were shown in Figure 2. The results of subgroup analysis were shown in Table 2 .

3.4. Heterogeneity and Publication Bias. There was no significant heterogeneity across these studies $\left(P_{\mathrm{H}}>0.05\right)$; therefore the fixed-effect models were performed. Publication bias was assessed by Begg's funnel plot, Begg's test, and Egger's test. The Begg's funnel plot showed that the shape of the funnel plot seemed symmetrical (Figure 3(a)). And there was no significant evidence of publication bias found in this metaanalysis (Table 3 ). The plot of sensitivity analysis was shown in Figure 3(b).

\section{Discussion}

The ERBB3 gene might play a key role in immune regulation and cytokine-induced pancreatic beta-cell apoptosis, which related to T1D pathogenesis [19-21]. The association between ERBB3 rs2292239 and T1D susceptibility has been identified in genome-wide association studies, such as TEDDY study [22-24]. However, only few studies evaluated ERBB3 gene polymorphism and T1D susceptibility in different ethnicities. Therefore, we conducted this meta-analysis. In this metaanalysis, 9 eligible case-control studies including 5369 T1D patients and 6920 controls were analyzed. The present study showed significant association between ERBB3 rs2292239 


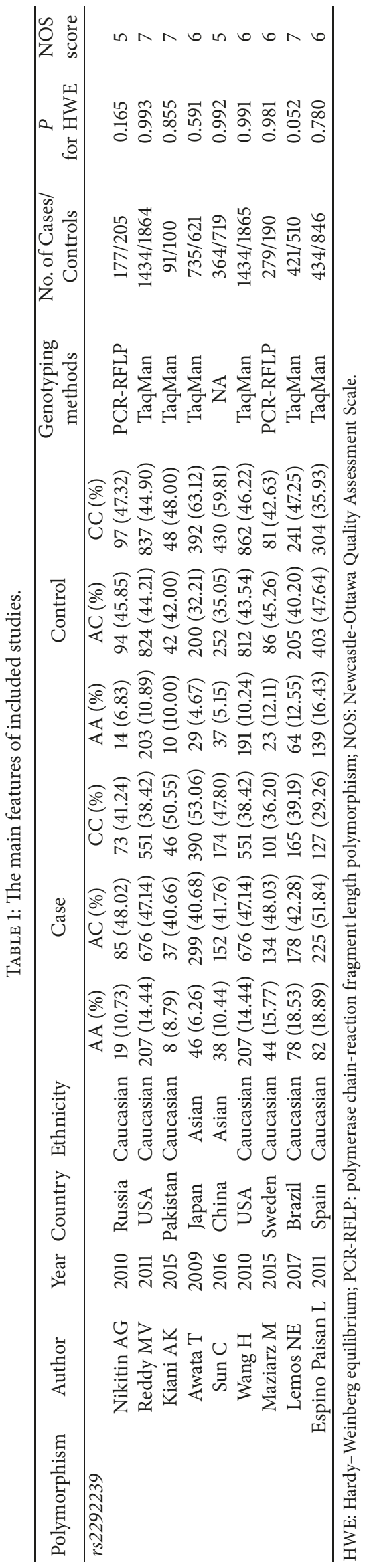



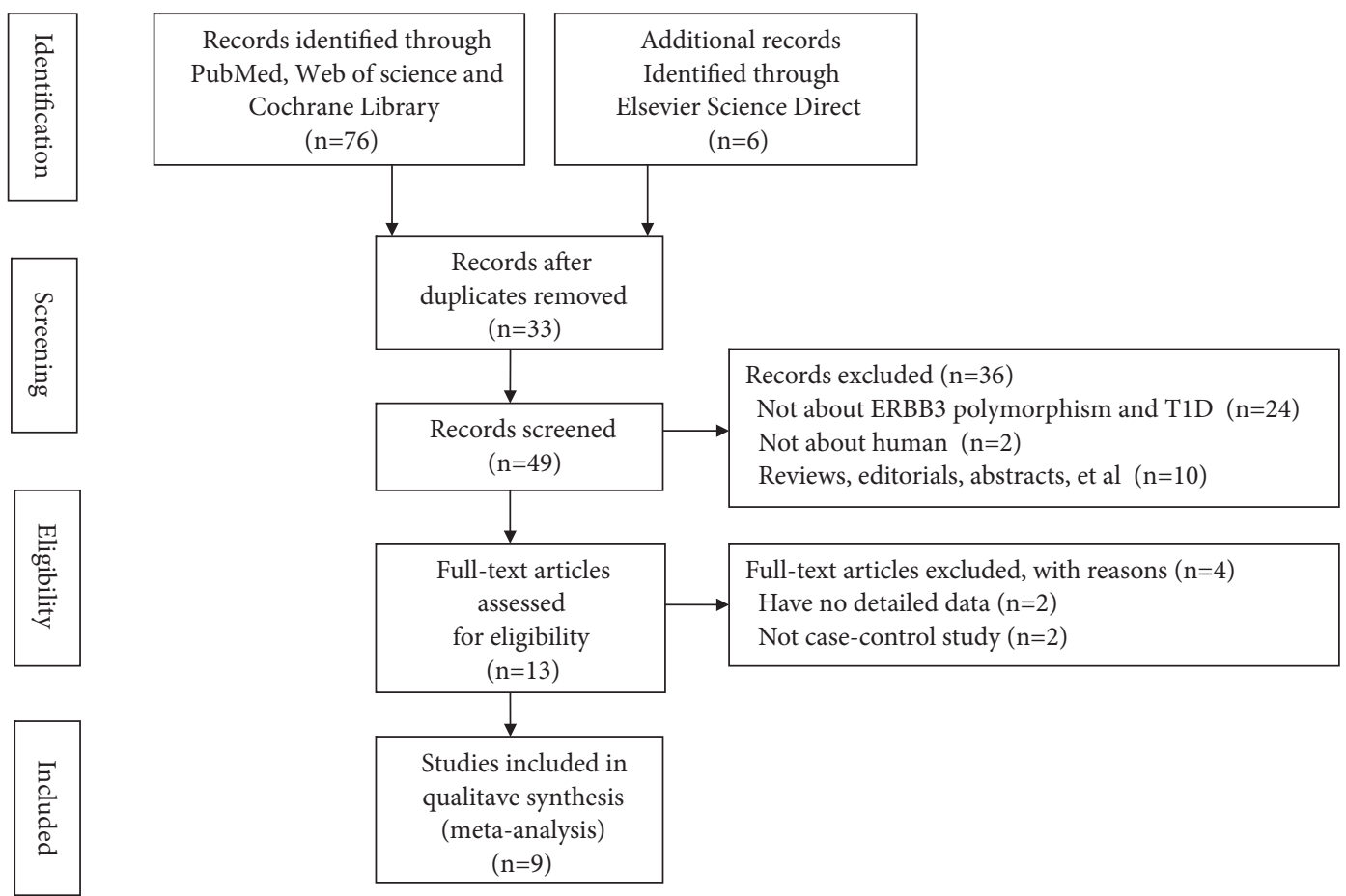

Figure 1: A flowchart of the included and excluded studies.

TABLE 2: The results of meta-analysis.

\begin{tabular}{|c|c|c|c|c|c|c|}
\hline \multirow{3}{*}{$\begin{array}{l}\text { Polymorphism } \\
\text { rs2292239 }\end{array}$} & \multicolumn{2}{|c|}{ Allelic model } & \multicolumn{2}{|c|}{ Dominant model } & \multicolumn{2}{|c|}{ Recessive model } \\
\hline & \multicolumn{2}{|c|}{ A versus $C$} & \multicolumn{2}{|c|}{$\mathrm{AA}$ versus $\mathrm{AC}+\mathrm{CC}$} & \multicolumn{2}{|c|}{$\mathrm{AA}+\mathrm{AC}$ versus $\mathrm{CC}$} \\
\hline & OR $(95 \% \mathrm{CI})$ & $P_{\mathrm{H}}$ & OR (95\% CI) & $P_{\mathrm{H}}$ & OR $(95 \% \mathrm{CI})$ & $P_{\mathrm{H}}$ \\
\hline overall & $1.292(1.224-1.364)$ & 0.450 & $1.426(1.275-1.594)$ & 0.636 & $1.374(1.277-1.479)$ & 0.732 \\
\hline \multicolumn{7}{|l|}{ Ethnicity } \\
\hline Caucasian & $1.262(1.190-1.339)$ & 0.762 & $1.395(1.239-1.570)$ & 0.805 & $1.332(1.228-1.446)$ & 0.894 \\
\hline Asian & $1.455(1.273-1.663)$ & 0.388 & $1.701(1.214-2.384)$ & 0.183 & $1.560(1.322-1.841)$ & 0.680 \\
\hline
\end{tabular}

$P_{\mathrm{H}}$ : the value of $P$ in the heterogeneity test.

polymorphism and T1D susceptibility under all genetic models. Similar results were found in subgroup analysis by ethnicity.

The ERBB3 gene is located on chromosome 12q13; some studies have shown that the protective genotypes for T1D are associated with higher ERBB3 mRNA level in peripheral blood mononuclear cells (PBMCs). ErbB3 protein can be expressed on the surface of CD11c+ cells (dendritic cells and monocytes) in peripheral blood after stimulation. Subjects with protective genotypes have significantly higher percentages of ERBB3+ monocytes and dendritic cells, and the percentages of $E R B B 3+$ cells are positively correlated with the ability of antigen presenting cells (APCs) to stimulate T cell proliferation [13]. Furthermore, as a member of the epidermal growth factor receptor (EGFR) family, ErbB3 is critical to the activation of the ERBB3-PI3K-Akt cascade induced by EGFR/ERBB3 heterodimers. Deficiency or inhibition of the $\mathrm{PI} 3 \mathrm{~K}$ pathway can lead to reduced numbers of regulatory
$\mathrm{T}$ cells and autoimmunity $[9,10,13]$. It suggests that the $E R B B 3$ gene might play an important role in potential T1D pathogenesis.

The rs2292239 SNP is located in intron 7 of ERBB3 gene and this SNP has significant functional effects. Some studies have shown that $r s 2292239$ associates with residual beta-cell function and metabolic, ERBB3 dysfunction could decrease basal and cytokine-induced apoptosis. The rs2292239-A allele might change ERBB3 expression in immune cells and pancreatic beta-cells, influencing APC function, immunity, and beta-cells apoptosis [9]. Moreover, rs2292239 has been associated with the production of T1D specific autoantibody [23]. Therefore, $r s 2292239$ might be involved in T1D pathogenesis and confer disease susceptibility.

Of course, there were some limitations in this metaanalysis. First, the number of included studies was not sufficient, which could not conduct comprehensive analysis. Second, our data of meta-analysis was from retrospective 


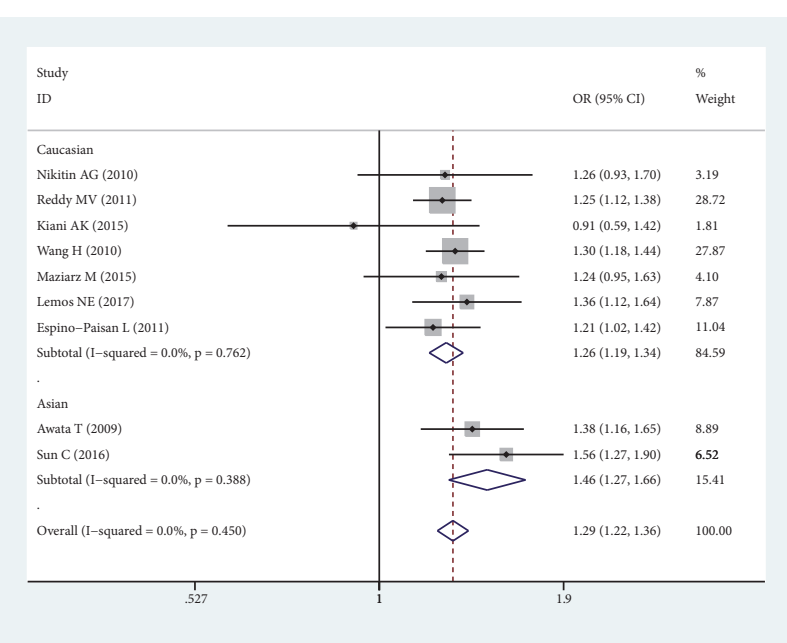

(a)

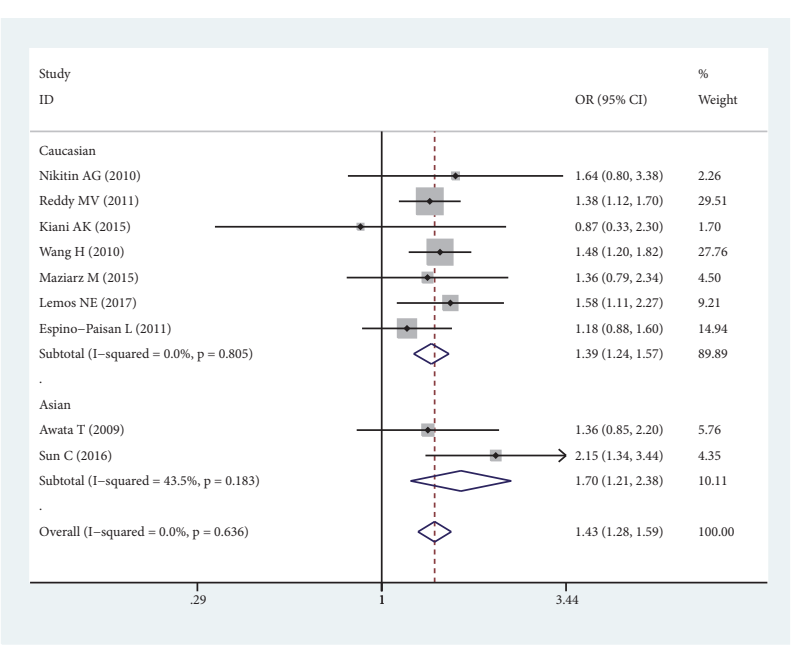

(b)

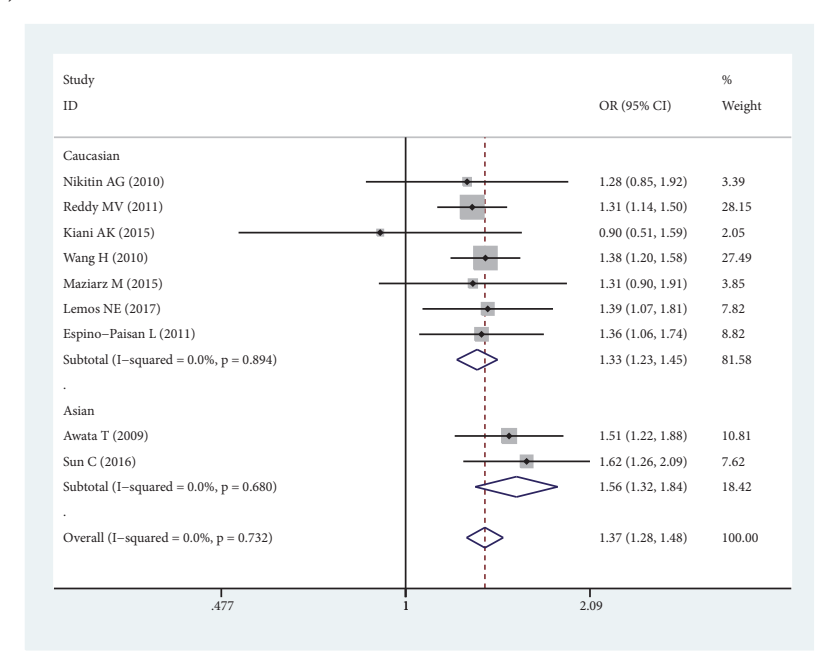

(c)

FIGURE 2: Forest plots for $r s 2292239$ polymorphism and the risk of T1D. (a) Forest plot for $r s 2292239$ polymorphism and the risk of T1D under Allelic model. (b) Forest plot for $r s 2292239$ polymorphism and the risk of T1D under Dominant model. (c) Forest plot for $r s 2292239$ polymorphism and the risk of T1D under Recessive model.

TABLE 3: The results of publication bias.

\begin{tabular}{lcccc}
\hline Polymorphism & \multicolumn{3}{c}{ Test of publication bias } \\
rs2292239 & $Z$ & $P$ & $t$ & $P$ \\
\hline Allelic model & -0.10 & 1.000 & -0.12 & 0.909 \\
Dominant model & 0.10 & 0.917 & 0.31 & 0.769 \\
Recessive model & 1.15 & 0.251 & -0.40 & 0.698 \\
\hline
\end{tabular}

studies, which may be related to the methodological deficiencies because the rs2292239 polymorphism in ERBB3 gene can be associated with multitude parameters, such as gender and environment. Third, our meta-analysis did not take those factors into account. All in all, the results should be interpreted with caution.
In conclusion, the present study indicates that $E R B B 3$ rs2292239 polymorphism is associated with T1D susceptibility. However, it is still necessary to conduct more large-scale studies to further explore the pathogenetic mechanisms of ERBB3 in T1D.

\section{Conflicts of Interest}

All members declare they have no conflicts of interest.

\section{Acknowledgments}

This study was supported by grants from the Anhui Medical University Doctoral research foundation (XJ201414) and Anhui province postdoctoral foundation (2017B237). 


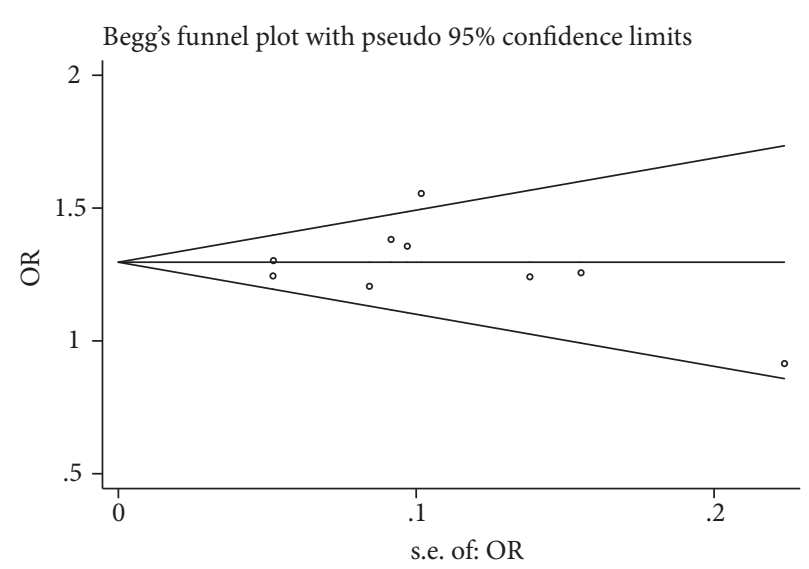

(a)

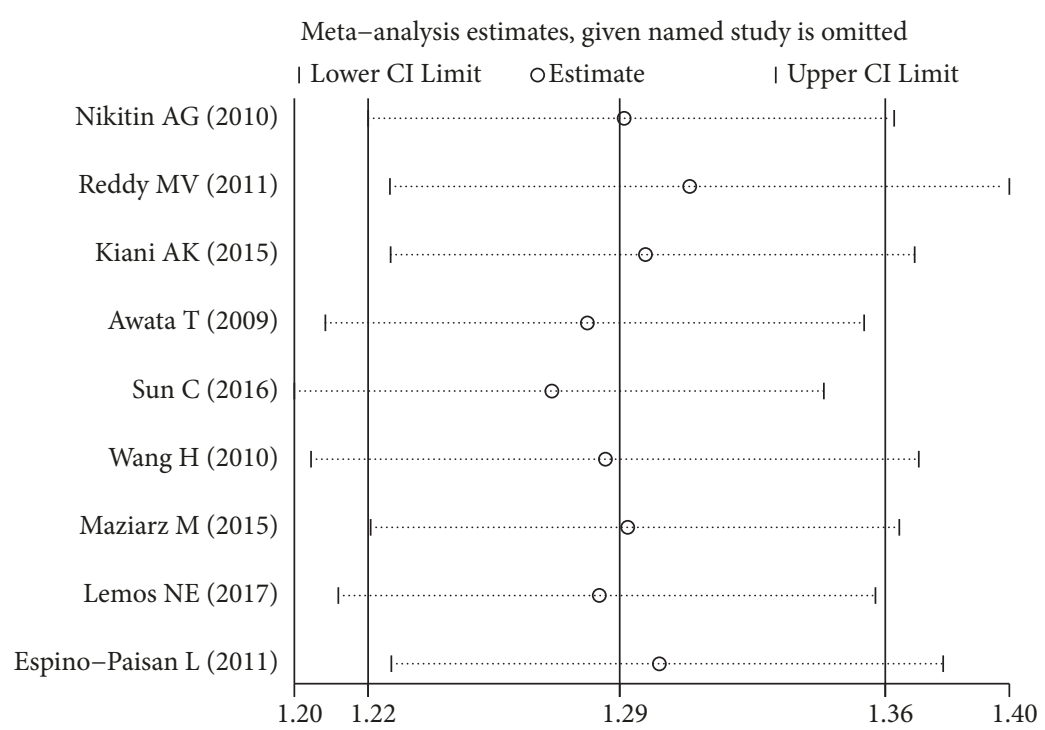

(b)

FIGURE 3: Results of Begg's funnel plot and sensitivity analysis. (a) Begg's funnel plot of rs2292239-A with T1D. (b) The sensitivity analysis results of $r s 2292239-A$ with T1D.

\section{References}

[1] M. J. Redondo, A. K. Steck, and A. Pugliese, "Genetics of type 1 diabetes," Pediatric Diabetes, vol. 19, no. 3, pp. 346-353, 2018.

[2] T. S. Assmann, G. C. Duarte, L. A. Brondani et al., "Polymorphisms in genes encoding miR-155 and miR-146a are associated with protection to type 1 diabetes mellitus," Acta Diabetologica, vol. 54, no. 5, pp. 433-441, 2017.

[3] J. Liu and H. Zhang, "Association between the Rs3087243 polymorphism and risk for diabetes: a meta-analysis," Genetics and Molecular Research, vol. 12, no. 4, pp. 6344-6350, 2013.

[4] M. P. Reddy, H. Wang, S. Liu et al., "Association between type 1 diabetes and GWAS SNPs in the southeast US Caucasian population," Genes \& Immunity, vol. 12, no. 3, pp. 208-212, 2011.

[5] D. K. Chellappan, N. S. Sivam, K. X. Teoh et al., "Gene therapy and type 1 diabetes mellitus," Biomedicine \& Pharmacotherapy, vol. 108, pp. 1188-1200, 2018.

[6] N. E. Lemos, C. Dieter, L. E. Dorfman et al., “The rs2292239 polymorphism in ERBB3 gene is associated with risk for type 1 diabetes mellitus in a Brazilian population," Gene, vol. 644, pp. 122-128, 2018.

[7] A. K. Kiani, P. John, A. Bhatti et al., "Association of 32 type 1 diabetes risk loci in Pakistani patients," Diabetes Research and Clinical Practice, vol. 108, no. 1, pp. 137-142, 2015.

[8] M. Maziarz, W. Hagopian, J. P. Palmer et al., "Non-HLA type 1 diabetes genes modulate disease risk together with HLA-DQ and islet autoantibodies," Genes \& Immunity, vol. 16, no. 8, pp. 541-551, 2015.

[9] S. Kaur, A. H. Mirza, C. A. Brorsson et al., "The genetic and regulatory architecture of ERBB3-type 1 diabetes susceptibility locus," Molecular and Cellular Endocrinology, vol. 419, pp. 83-91, 2015.

[10] C. Sun, H. Wei, X. Chen et al., "ERBB3 -rs2292239 as primary type 1 diabetes association locus among non- HLA genes in Chinese," Meta Gene, vol. 9, pp. 120-123, 2016.

[11] K. L. Keene, A. R. Quinlan, X. Hou et al., "Evidence for two independent associations with type 1 diabetes at the 12q13 locus," Genes \& Immunity, vol. 13, no. 1, pp. 66-70, 2012. 
[12] T. Awata, E. Kawasaki, S. Tanaka et al., "Association of type 1 diabetes with two loci on 12q13 and 16p13 and the influence coexisting thyroid autoimmunity in Japanese," The Journal of Clinical Endocrinology \& Metabolism, vol. 94, no. 1, pp. 231-235, 2009.

[13] H. Wang, Y. Jin, M. V. Linga Reddy et al., "Genetically dependent ERBB3 expression modulates antigen presenting cell function and type 1 diabetes risk," PLoS ONE, vol. 5, no. 7, Article ID el1789, 2010.

[14] J. D. Cooper, N. M. Walker, B. C. Healy, D. J. Smyth, K. Downes, and J. A. Todd, "Analysis of 55 autoimmune disease and type II diabetes loci: further confirmation of chromosomes 4q27, $12 \mathrm{q} 13.2$ and $12 \mathrm{q} 24.13$ as type I diabetes loci, and support for a new locus, 12q13.3-q14.1," Genes \& Immunity, vol. 10, no. S1, pp. S95-S120, 2009.

[15] A. G. Nikitin, E. Y. Lavrikova, Y. A. Seregin et al., "Association of the polymorphisms of the ERBB3 and SH2B3 genes with type 1 diabetes," Journal of Molecular Biology, vol. 44, no. 2, pp. 228$232,2010$.

[16] L. Hartling, A. Milne, M. P. Hamm et al., "Testing the Newcastle Ottawa Scale showed low reliability between individual reviewers," Journal of Clinical Epidemiology, vol. 66, no. 9, pp. 982-993, 2013.

[17] D. Moher, A. Liberati, and J. Tetzlaff, "Preferred reporting items for systematic reviews and meta-analyses: the PRISMA statement," Journal of Clinical Epidemiology, vol. 62, no. 10, pp. 1006-1012, 2009.

[18] D. F. Stroup, J. A. Berlin, S. C. Morton et al., "Meta-analysis of observational studies in epidemiology: a proposal for reporting Meta-analysis Of Observational Studies in Epidemiology (MOOSE) group," Journal of the American Medical Association, vol. 283, no. 15, pp. 2008-2012, 2000.

[19] L. Espino-Paisan, H. de la Calle, M. Fernández-Arquero et al., "Polymorphisms in chromosome region 12q13 and their influence on age at onset of type 1 diabetes," Diabetologia, vol. 54, no. 8, pp. 2033-2037, 2011.

[20] D. M. Nyaga, M. H. Vickers, C. Jefferies, J. K. Perry, and J. M. O'Sullivan, "Type 1 diabetes mellitus-associated genetic variants contribute to overlapping immune regulatory networks," Frontiers in Genetics, vol. 9, Article ID 00535, 2018.

[21] B. Saberzadeh-Ardestani, R. Karamzadeh, M. Basiri et al., “Type 1 diabetes mellitus: Cellular and molecular pathophysiology at a glance," Cell, vol. 20, no. 3, pp. 294-301, 2018.

[22] J. P. Krischer, K. F. Lynch, Å. Lernmark et al., "Genetic and environmental interactions modify the risk of diabetes-related autoimmunity by 6 years of age: the TEDDY study," Diabetes Care, vol. 40, no. 9, pp. 1194-1202, 2017.

[23] C. Törn, D. Hadley, and H.-S. Lee, "Role of type 1 diabetesassociated SNPs on risk of autoantibody positivity in the TEDDY study," Diabetes, vol. 64, no. 5, pp. 1818-1829, 2015.

[24] J. A. Todd, N. M. Walker, J. D. Cooper et al., "Robust associations of four new chromosome regions from genome-wide analyses of type 1 diabetes," Nature Genetics, vol. 39, no. 7, pp. 857-864, 2007. 


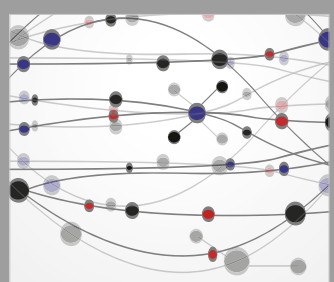

The Scientific World Journal
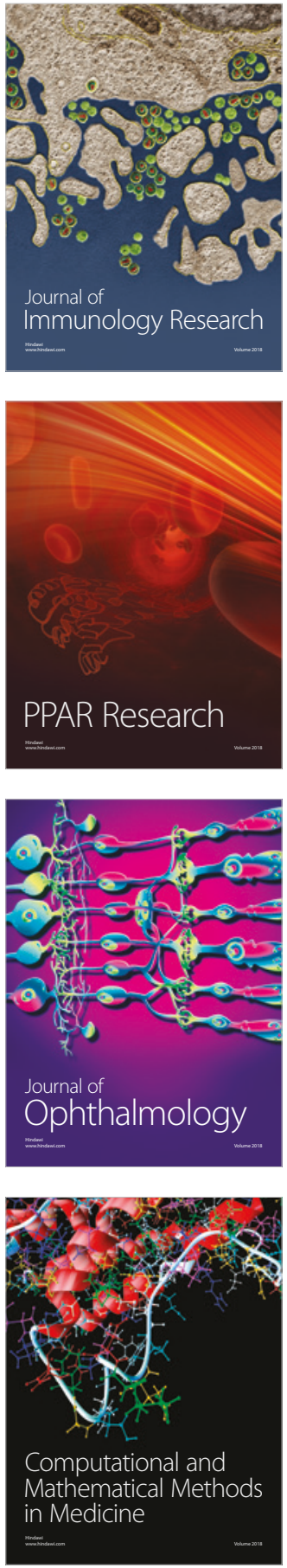

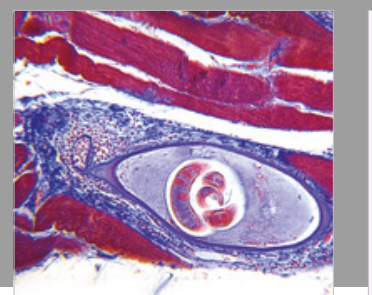

Gastroenterology Research and Practice

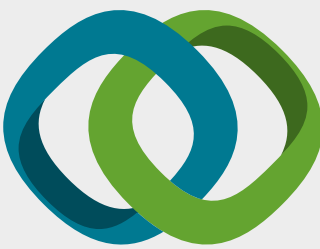

\section{Hindawi}

Submit your manuscripts at

www.hindawi.com
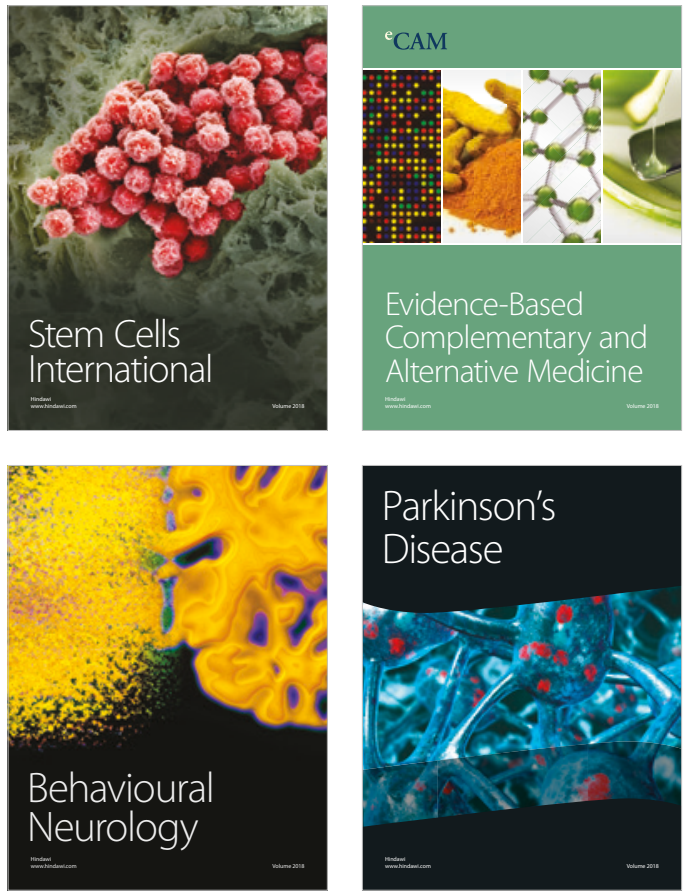

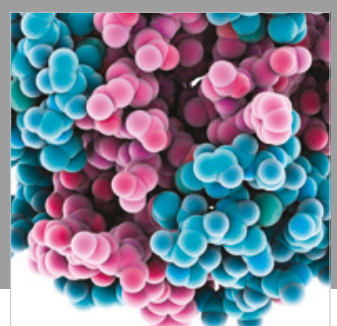

ournal of

Diabetes Research

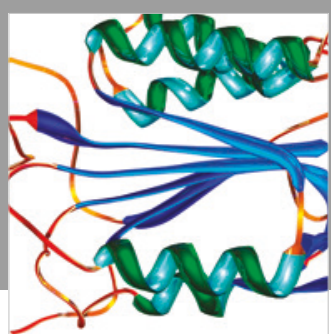

Disease Markers
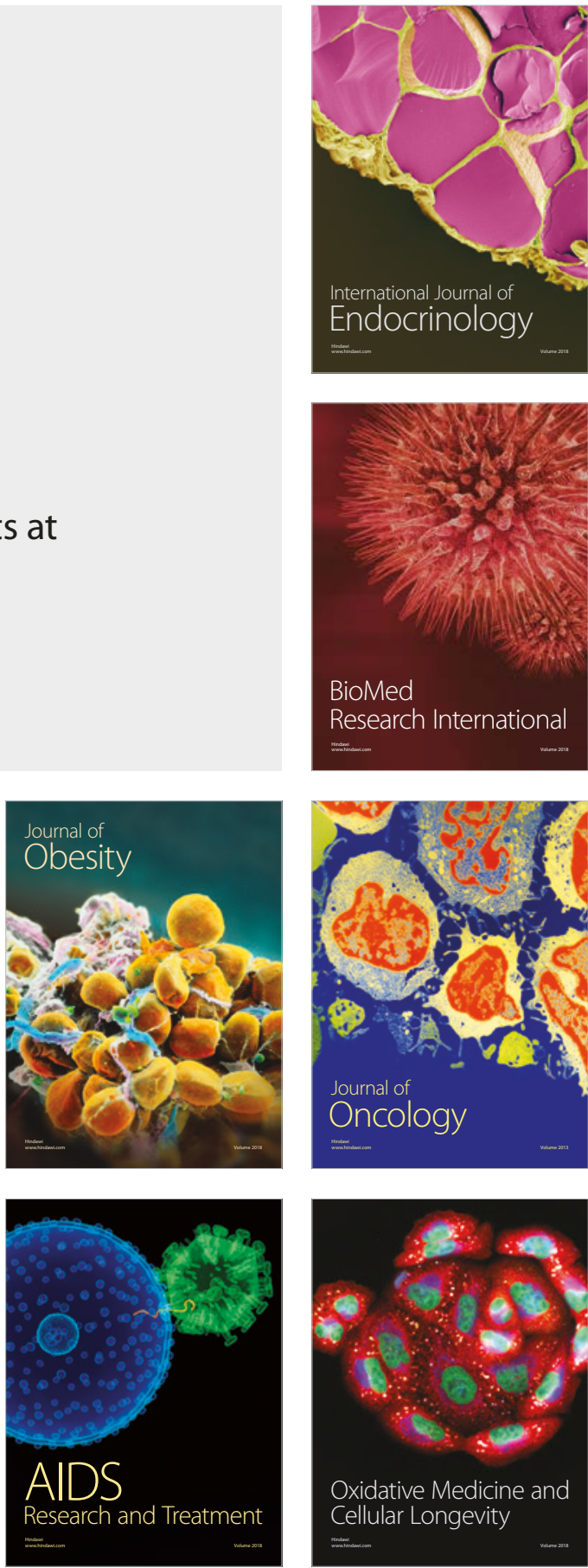